\title{
In vivo antiplatelet effect of intravenous alum in rabbits
}

F.I. Mohammed ${ }^{1}$ and Y.A. Shafagoj ${ }^{1}$

$$
\begin{aligned}
& \text { تأثير حقن الثبّ في الوريد على مضاد الصفيحات في الأرانب }
\end{aligned}
$$

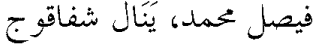

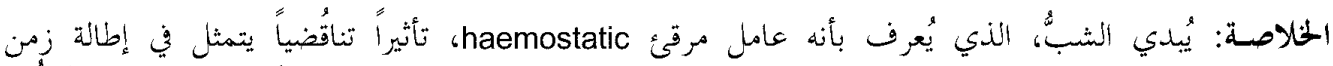

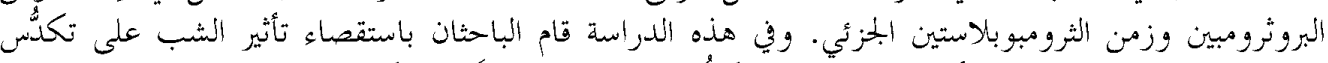

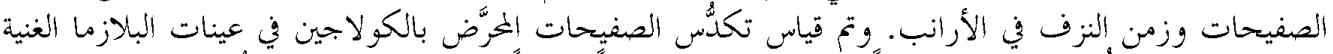

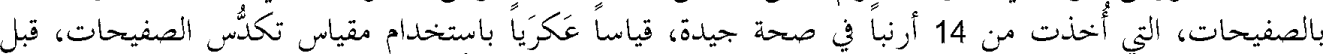

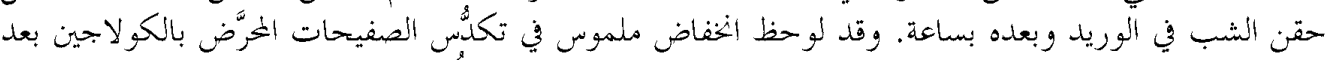

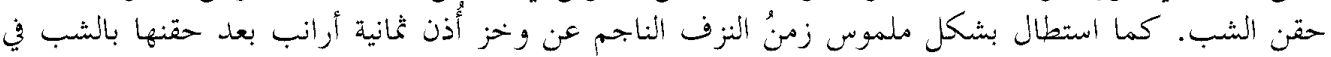

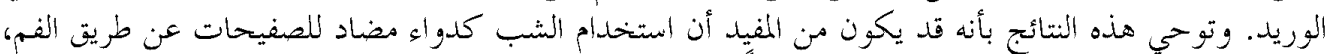

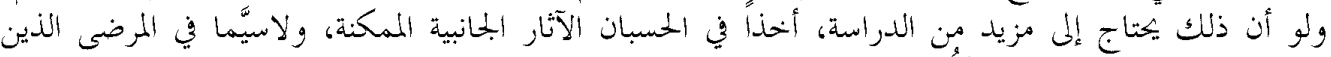

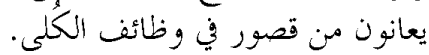

ABSTRACT Traditionally known as a haemostatic agent, alum shows a paradoxical effect of increased prothrombin and partial thromboplastin times. This study investigated the in vivo effect of alum on platelet aggregation and bleeding time in rabbits. The collagen-induced platelet aggregation of platelet-rich plasma samples from 14 healthy rabbits was measured turbidometrically using a platelet aggregometer, before and 1 hour after intravenous injection of alum. Collagen-induced platelet aggregation was significantly reduced after alum injection. Bleeding time from an ear puncture in 8 rabbits was also significantly prolonged after intravenous alum injection. These results suggest that the use of alum as an oral antiplatelet drug could be explored further, taking into account possible side-effects especially in renal compromised patients.

\section{Effet antiplaquettaire in vivo de l'alun injecté par voie intraveineuse chez des lapins}

RÉSUMÉ Traditionnellement connu comme agent hémostatique, l'alun montre un effet paradoxal d'allongement des temps de prothrombine et de thromboplastine partielle. La présente étude a examiné l'effet in vivo de l'alun sur l'agrégation plaquettaire et le temps de saignement chez des lapins. L'agrégation plaquettaire induite par le collagène dans des échantillons de plasma riche en plaquettes de 14 lapins sains a été mesurée par turbidimétrie en utilisant un agrégomètre, avant et une heure après une injection intraveineuse d'alun. L'agrégation plaquettaire induite par le collagène était significativement réduite après l'injection d'alun. Le temps de saignement après incision à l'oreille chez 8 lapins était significativement prolongé après l'injection intraveineuse d'alun. Ces résultats semblent indiquer que l'utilisation de l'alun en tant qu'antiplaquettaire oral pourrait faire l'objet d'études complémentaires, en tenant compte des effets secondaires éventuels notamment chez les patients dont la fonction rénale est altérée.

${ }^{1}$ Department of Physiology and Biochemistry, Faculty of Medicine, University of Jordan, Amman, Jordan (Correspondence to F.l. Mohammed: fmmed@ju.edu.jo).

Received: 11/01/05; accepted: 12/05/05

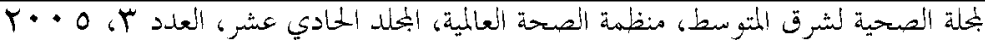




\section{Introduction}

Alum (aluminium potassium sulfate) is a food additive and traditional remedy used to stop superficial bleeding from minor abrasions or cuts. Its astringent properties contribute to its efficacy in the treatment of intravesical haemorrhage caused by prostate and bladder cancer $[1,2]$ or hemorrhagic cystitis [3]. Alum can also control haemorrhage from advanced rectal carcinoma [4] or oesophageal varices [5]. Alum proved to be safe and effective and thus remains the drug of choice for persistent vesical haematuria [6]. In addition, mouth rinses containing alum have been shown to reduce dental plaques and can therefore be useful in preventive dentistry $[7,8]$.

The mechanism by which alum halts bleeding is not clearly understood. Protein precipitation and/or vasoconstriction are proposed mechanisms. Precipitation occurs primarily on the cell surface and superficial interstitial spaces. This leads to decreased capillary permeability, contraction of intercellular space, vasoconstriction, hardening of the capillary endothelium and a reduction in oedema, inflammation and exudate $[9,10]$.

Only 2 studies have followed its effect on the blood. Surprisingly, both reported elevated prothrombin and partial thromboplastin times with high serum aluminium levels after either intravesical irrigation [11] or accidental exposure to alum at work [12]. This paradox in the mechanism of action of alum is confirmed by our previous report that human platelet aggregation induced by collagen, epinephrine, adenosine diphosphate (ADP) and thrombin were inhibited by in vitro treatment with alum [13]. However, to the best of our knowledge, the antiaggregation effect of alum has not yet been investigated in vivo. Therefore, to further investigate this apparent contradiction in the mechanism of action of alum, we evaluated the in vivo effect of alum in terms of collagen-induced platelet aggregation and bleeding time. We aimed to elucidate if the in vitro properties of alum were also observed in vivo.

\section{Methods}

Ethical approval for the study was obtained from the Institutional Animal Care Committee of the University of Jordan, and the Committee guidelines were followed to minimize pain and discomfort during the entire experimental period.

\section{Materials}

Local inbred healthy male adult white rabbits were used. The animals were maintained on a regular diet with a locally purchased proprietary rabbit food mix and water ad libitum. The animal treatments were made between 10.00 and 12.00 hours.

Collagen from calfskin was purchased from Sigma, St. Louis, Missouri, USA. Aluminium potassium sulfate ( $>99 \%$ pure) was obtained from local sources.

\section{Platelet aggregation study}

For the platelet aggregation study, 14 rabbits were used with a mean (standard deviation) body weight of $2.2(0.23) \mathrm{kg}$, range $1.9-2.7 \mathrm{~kg}$.

The rabbits were injected in the marginal ear vein with alum at $5 \mathrm{mg} / \mathrm{kg}$ body weight. Alum was dissolved in normal saline in a concentration of $1 \mathrm{mg} / \mathrm{mL}$, and thus $5 \mathrm{~mL} / \mathrm{kg}$ of this solution was injected. Blood samples were drawn from the central ear artery of study rabbits before the experiment started and 1 hour after injection of alum.

المُلة الصحية لشرق المتوسط، منظمة الصحة العالمية، المجلد الحمادي عشر، العلد ب، 0 • + 
Blood was collected into trisodiumcitrated tubes through citrated syringes and butterflies. Citrated blood was then centrifuged at $1000 \mathrm{rpm}(250 \times \mathrm{g})$ for 10 minutes at room temperature to obtain the plateletrich plasma (PRP) fraction from the supernatant while excluding the buffy coat layer. The PRP was left for half an hour to prevent platelet shock. The remaining blood was centrifuged at $2500 \mathrm{rpm}(1500 \times \mathrm{g})$ for 10 minutes to obtain the platelet-poor plasma (PPP) fraction. The PPP was used as a blank to set the baseline for the aggregometer. Platelet aggregation was induced by adding $20 \mu \mathrm{L}$ of collage solution $(91 \mu \mathrm{g} /$ $\mathrm{mL})$ to $200 \mu \mathrm{L}$ of PRP. The reaction mixture was stirred magnetically at $1000 \mathrm{rpm}$ and percentage aggregation was recorded at 30 -second intervals for up to 5 minutes until aggregation was complete. Platelet aggregation was monitored turbidometrically with continuous reading of light transmission using an aggregometer (model PAP-4, Bio/Data Corporation, Horsham, Pennsylvania, USA) according to the method of Born [14].

\section{Bleeding time study}

For the bleeding time study, 8 rabbits were used with a mean (SD) body weight of 2.3 $(0.24) \mathrm{kg}$, range $2.0-2.6 \mathrm{~kg}$. The rabbits used for platelet aggregation could not be used at the same time for bleeding time experiments because of the stress of drawing blood on the animals and the injection site on the ear.

The rabbits were injected with alum at 5 $\mathrm{mg} / \mathrm{kg}$ body weight through the marginal ear vein and the other ear was used for the measurement of bleeding time. The rabbit's ear was punctured using a routine automatic lancet and filter paper and the same ear was punctured in another place 1 hour after infection. Skin bleeding time was assessed before the experiment started and after in- jection of alum. Bleeding time was measured using a stopwatch from the time of puncture until the time bleeding stopped and was determined by the same person.

\section{Follow-up}

The rabbits were followed for several weeks following the injection. The alum dose used had a mortality rate of zero and none of the animals show any gross visual signs of aluminium toxicity such as seizures, anorexia, vomiting or coma. Alum toxicity in terms of renal impairment, however, was not assessed in this study.

\section{Controls}

Two groups of parallel experiments were conducted by injecting rabbits with $5 \mathrm{~mL} /$ $\mathrm{kg}$ normal saline. Platelet aggregation in one group, and bleeding time in a second group, were measured before and after injection of normal saline. No changes were noted in the above parameters due to normal saline injection (data not shown).

\section{Statistical analysis}

The data are presented as mean [standard error (SE)]. Comparisons between data from control and alum-treated rabbits were made with the 2-tailed paired Student $t$-test and a $P$ value $<0.05$ was considered statistically significant.

\section{Results}

The results showed that alum significantly decreased the collagen-induced platelet aggregation of platelet-rich plasma 1 hour after a single intravenous injection from a mean of $68.6 \%$ to $26.4 \%(P<0.05)$ (Figure 1). These inhibitory effects were significant as early as 30 seconds following the addition of collagen and reached a maximum at 3 minutes (Figure 2). The same 


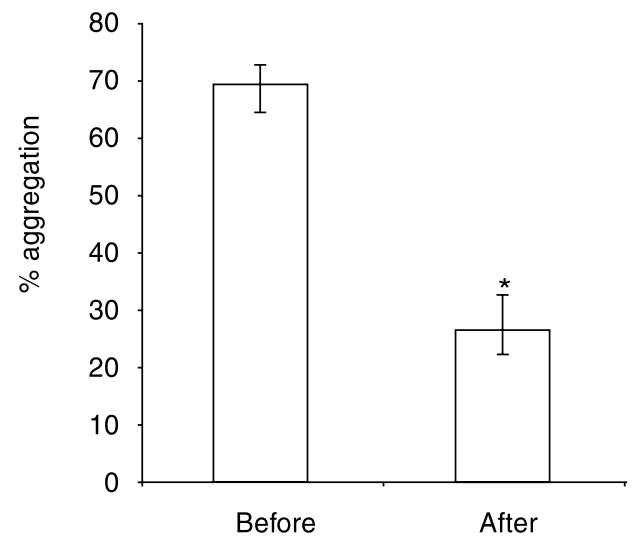

Figure 1 Mean percentage platelet aggregation of platelet-rich plasma 3 minutes after collagen induction, before and 1 hour after intravenous alum injection to rabbits $(n=14)$. Bars indicate standard error; ${ }^{*} P<0.05$

trend of inhibition 0.5 hour and 2 hours after intravenous alum injection was recorded (data not shown).
Bleeding time from an ear puncture in rabbits was prolonged significantly from a mean of 2.36 minutes to 3.79 minutes $(P<$ $0.05)$ after single intravenous alum injection (Figure 3).

Control rabbits were injected intravenously with normal saline alone and did not show any change in platelet aggregation or bleeding time.

\section{Discussion}

Platelets are believed to play a key role in the pathogenesis of atherosclerosis and acute coronary syndromes and therefore antiplatelet therapy may offer clinical benefits in the prevention of heart attacks and strokes. The haemostatic platelet function is mediated through their aggregation response to various endogenous agonists such as collagen, thrombin, adenosine diphosphate (ADP), adrenaline and 5hydroxtryptamine (5-HT) [15]. In addition, bleeding time has been advocated as a sim-

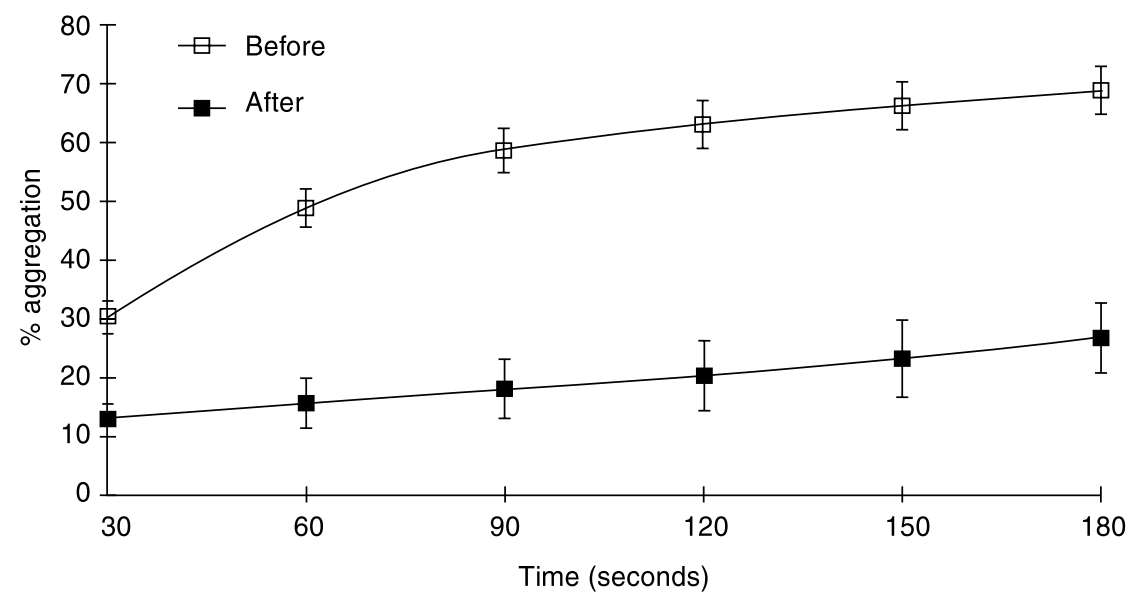

Figure 2 Mean percentage platelet aggregation of platelet-rich plasma 30 seconds to 3 minutes after collagen induction, before and 1 hour after intravenous alum injection to rabbits $(n=14)$. Bars indicate standard error

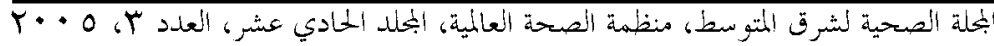




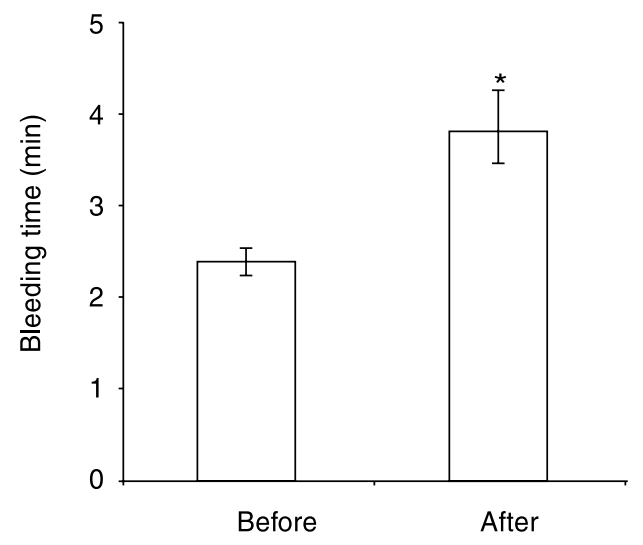

Figure 3 Mean bleeding time of an ear puncture, before and 1 hour after intravenous alum injection to rabbits $(n=8)$. Bars indicate standard error; ${ }^{\star} P<0.05$

ple test for platelet function [16]. Alum stops superficial bleeding and is used to stop intractable haematuria caused by a multiple array of causes. The mechanism of this action has not yet been properly investigated.

The present study focused on the responsiveness to in vivo administration of alum in terms of collagen-induced platelet aggregation and bleeding time. Opposite to what would be predicted, alum inhibited collagen-induced platelet aggregation and prolonged bleeding time when administered parenterally. The question of why a haemostatic agent such as alum inhibits platelet aggregation needs to be resolved. However, the current findings are consistent with our previous in vitro results showing that alum inhibited human platelet aggregation induced by collagen, epinephrine, ADP and thrombin in vitro [12].

Collagen, being a physiologically important activating agent, induces aggregation through forming thromboxanes. Its mech- anism of action involves binding to plasma von Willebrand factor that activates platelet receptors glycoprotein IIb/IIIa (GP IIb/ IIIa) [17-19]. It is conceivable that alum inhibits collagen-induced platelet aggregation through competing for their GP IIb/ IIIa surface receptors. Although collagen and ADP react with the same receptors, collagen forms thromboxane but ADP does not. Alum probably works through a mechanism different than that of aspirin. For instance, aspirin inhibits collagen but not ADP-induced platelet aggregation [20]. However, alum inhibits both collagen and ADP-induced platelet aggregation [13].

The importance of our findings needs to be investigated thoroughly. For instance, inhibitors of the platelet GP IIb/IIIa would be of great clinical value as anti-platelet agents. Alum is absorbed by the gastrointestinal tract when given orally, which can be enhanced by citric acid [21]. If alum conforms to this principle it would intriguing to explore its potential use as an antiplatelet drug.

Extrapolating data from animals to humans should be approached with caution. Systemic toxicity and dose-response studies on alum would be needed before making any conclusions regarding its clinical values [22,23]. Although the safety of alum irrigation has been established in many studies [11], its toxicity after intravenous injection has to be addressed thoroughly. For instance, patients with a damaged urinary bladder wall or renal impairment are at increased risk of developing aluminium toxicity. Intact renal function is essential for rapid disposal of a parenteral aluminium dose [24]. Therefore, patients with renal impairment are at increased risk of developing encephalopathy, which might be a major drawback against routine use of alum $[2,25]$. 


\section{Conclusion}

This study indicates that alum inhibits platelet aggregation and prolongs bleeding time in vivo. Alum could be a costeffective anti-platelet agent, but its sideeffects would need to be addressed carefully. The dose-response and elimination rate of alum would need to be studied to elucidate the clinical importance of these findings.

\section{Acknowledgements}

This work was supported by grant 439/9798 from the Scientific Deanship of the University of Jordan. The authors thank Professor Abdullah Al-Abbadi for his scientific advice. We also thank Mrs Amal AbuRagheb for her excellent technical work.

\section{References}

1. Kavoussi LR, Gelstein LD, Andriole GL. Encephalopathy and an elevated serum aluminum level in a patient receiving intravesical alum irrigation for severe urinary hemorrhage. Journal of urology, 1986, 136:665-7.

2. Shoskes DA et al. Aluminum toxicity and death following intravesical alum irrigation in patients with renal impairment. Journal of urology, 1992, 147:697-9.

3. Seear MD, Dimmick JE, Rogers PC. Acute aluminum toxicity after continuous intravesical alum irrigation for hemorrhagic cystitis. Urology, 1990, 36:353-4.

4. Paes TR et al. Alum solution in the control of intractable haemorrhage from advanced rectal carcinoma. British journal of surgery, 1986, 73:192.

5. Nishida $\mathrm{R}$ et al. A sclerosant with astringent properties developed in China for oesophageal varices: comparison with ethanolamine oleate and polidocanol. Journal of gastroenterology and hepatology, 1999, 14:481-8.

6. Praveen BV, Sankaranarayanan A, Vaidyanathan S. A comparative study of intravesical instillation of 15 (s) $15 \mathrm{Me}$ alpha and alum in the management of persistent hematuria of vesical origin. International journal of clinical pharmacology, therapy, and toxicology, 1992, 30:7-12.
7. Donovan TE, Gandara BK, Nemetz H. Review and survey of medicaments used with gingival retraction cords. Journal of prosthetic dentistry, 1985, 53:52531.

8. Olmez $\mathrm{A}$ et al. Effect of alum-containing mouthrinse in children for plaque and salivary levels of selected oral microflora. Journal of clinical pediatric dentistry, 1998, 22:335-41.

9. Arrizabalaga $\mathrm{M}$ et al. Treatment of massive haematuria with aluminous salts. British journal of urology, 1987, 60:2236.

10. Ostroff EB, Chenault OW Jr. Alum irrigation for the control of massive bladder hemorrhage. Journal of urology, 1982, 128:929-30.

11. Goswami AK et al. How safe is 15 alum irrigation in controlling intractable vesical hemorrhage? Journal of urology, 1993, 149:264-7.

12. Waldron-Edward D, Chan P, Skoryna SC. Increased prothrombin time and metabolic changes with high serum aluminum levels following long-term exposure to Bayer-process alumina. $\mathrm{Ca}$ nadian Medical Association journal, 1971, 105:1297-9.

13. Mohammed FI, Shafagoj YA. Antiaggregation effect of alum on human platelets.

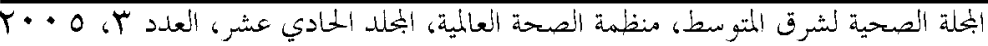


International journal of clinical pharmacology and therapeutics, 2001, 39:3224.

14. Born GVR. Aggregation of blood platelets by adenosine diphosphate and its reversal. Nature, 1962, 194:927-9.

15. Blockmans D, Deckmyn H, Vermylen J. Platelet activation. Blood reviews, 1995, 9:143-56.

16. Wagner SJ et al. Assessment of the hemostatic effectiveness of human platelets treated with aminomethyltrimethyl psoralen and UV A light using a rabbit ear bleeding time technique. Blood, 1993, 82:3489-92.

17. Kotite NJ, Staros JV, Cunningham LW. Interaction of specific platelet membrane proteins with collagen: evidence from chemical cross-linking. Biochemistry, 1984, 23:3099-104.

18. Fujimoto T, Hawiger J. Adenosine diphosphate induces binding of von Willebrand factor to human platelets. Nature, 1982, 297:154-6.

19. Gralnick HR, Williams SB, Coller BS. Fibrinogen competes with von Willebrand factor for binding to the glycoprotein Ilb/ IIla complex when platelets are stimulated with thrombin. Blood, 1984, 64: 797-800.
20. Naito $\mathrm{J}$ et al. Effects of thromboxane synthetase inhibitors on aggregation of rabbit platelets. European journal of pharmacology, 1983, 91:41-8.

21. Deng $Z$ et al. Effect of oral aluminum and aluminum citrate on blood level and short-term tissue distribution of aluminum in the rat. Biological trace element research, 1998, 63:139-47.

22. Wilhelm $M$ et al. Single-dose toxicokinetics of aluminum in the rat. Archives of toxicology, 1992, 66:700-5.

23. Bertholf $R L$ et al. A long-term intravenous model of aluminum maltol toxicity in rabbits: tissue distribution, hepatic, renal, and neuronal cytoskeletal changes associated with systemic exposure. Toxicology and applied pharmacology, 1989, 98:58-74.

24. Phelps KR et al. Encephalopathy after bladder irrigation with alum: case report and literature review. American journal of the medical sciences, 1999, 318:1815.

25. Moreno $A$ et al. High serum aluminium levels and acute reversible encephalopathy in a 4-year-old boy with acute renal failure. European journal of pediatrics, 1991, 150:513-4. 